\title{
PENGGUNAAN PERLAKUAN ANESTESI TERHADAP MASA SIUMAN IKAN MAS (Cyprinus carpio Linn.)
}

\author{
Sri Sukari Agustina \\ Staf Pengajar Fakultas Perikanan UNISMUH Luwuk Kabupaten Banggai \\ Email : asrisukari@yahoo.com
}

\begin{abstract}
Abstrak
Tujuan daripada penelitian ini adalah untuk mengkaji dan menganalisis penggunaan perlakuan anestesi terhadap masa siuman ikan mas (Cyprinus carpio Linn.). Penelitian ini dilaksanakan pada akhir bulan Mei sampai awal Juni 2012 di laboratorium Stasiun Karantina Ikan Kelas II Luwuk Banggai.Sedangkan hewan uji yang dijadikan sampel diambil dari Balai Benih Ikan Toili Kabupaten Banggai dengan ukuran 10-20 gram. Penelitian ini terdiri atas 3 perlakuan anestesi, yaitu perlakuan A (penggunaan quinaldine $1 \mathrm{cc} / 10 \mathrm{~L}$ ), perlakuan $\mathrm{B}$ (penggunaan suhu $8^{\circ} \mathrm{C}$ ) dan perlakuan $\mathrm{C}$ (penggunaan quinaldine $1 \mathrm{cc} / 10 \mathrm{~L}$ dan suhu $8^{\circ} \mathrm{C}$ ). Masa siuman diukur atau diamati pada saat setelah ikan pingsan sampai kondisi ikan menjadi siuman. Hasil penelitian menunjukkan bahwa penggunaan perlakuan anestesi teehadap masa siuman ikan mas yang terbaik adalah penggabungan penggunaan quinaldine $1 \mathrm{cc} / 10 \mathrm{~L}$ dan penggunaan suhu suhu $8{ }^{\circ} \mathrm{C}$.
\end{abstract}

Kata kunci: anestesi, masa siuman, ikan mas

\section{PENDAHULUAN}

Dewasa ini, permintaan konsumen akan komoditas perikanan dalam bentuk hidup dirasakan semakin besar dan berkembang, terutama untuk jenis-jenis ikan yang mempunyai nilai ekonomis tinggi seperti lobster, udang, ikan karang dan beberapa jenis ikan air tawar. Salah satu jenis ikan air tawar yang menjadi andalan komoditas perikanan masyarakat dalam bentuk hidup yang semakin meningkat dan berkembang, baik untuk konsumsi lokal, regional, maupun peluang untuk tujuan ekspor adalah ikan mas (Cyprinus carpio Linn). Hal ini sejalan dengan potensi dan sumberdaya ikan tersebut yang terus berkembang, baik dalam produksi maupun area kolam budidayanya.

Persaingan perdagangan ikan mas di pasar lokal maupun regional dirasakan semakin keras dan ketat, persaingan ini akan terus meningkat pada tahun mendatang. Dalam rangka meningkatkan daya saing perdagangan tersebut, berbagai tindakan telah dilakukan diantaranya adalah perubahan transportasi dan perdagangan ikan dalam bentuk segar mati menjadi dalam bentuk segar dan hidup. Perdagangan ikan dalam bentuk segar dan hidup memerlukan teknologi yang sesuai dan tepat dengan tuntutan komoditi, salah satu cara yang dapat dilakukan adalah pembiusan terhadap ikan mas pada saat transportasi. Pembiusan ini diharapkan akan mengurangi resiko kematian yang tinggi, dan efesien. Salah satu metode yang digunakan yaitu penggunaan suhu rendah dan bahan anti metabolik. Metode ini digunakan pada ikan hidup yang dibuat dalam kondisi terbius sebelum dikemas dan ditransportasi (Berka, 1986).

Tujuan penelitian adalah untuk mengkaji dan menganalisis penggunaan perbedaan perlakuan anestesi terhadap masa siuman ikan mas (Cyprinus carpio Linn.). 


\section{METODE PENELITIAN}

Penelitian ini dilaksanakan pada akhir bulan Mei sampai awal Juni 2012 di laboratorium Stasiun Karantina Ikan Kelas II Luwuk Banggai, sedangkan hewan uji yang dijadikan sampel diambil dari Balai Benih Ikan Toili Kabupaten Banggai. Hewan uji yang digunakan adalah ikan mas yang berukuran 10-20 gram dengan panjang 8-10 cm yang diperoleh dari Balai Benih Ikan Toili Kabupaten Banggai. Padat penebaran 1 ekor/liter. Dasar penentuan kepadatan ini sesuai dengan pendapat Suseno (1999) bahwa kepadatan yang baik untuk transportasi benih yaitu berkisar antara 1-2 ekor/liter. Jenis pakan uji yang digunakan dalam penelitian ini yakni pakan pellet dengan dosis pemberian pakan selama aklimatisasi 3\% dari bobot biomass ikan. Penelitian ini terdiri atas 3 perlakuan metode pembiusan, yaitu perlakuan A (penggunaan quinaldine $1 \mathrm{cc} / 10 \mathrm{~L}$ ), perlakuan $\mathrm{B}$ (penggunaan suhu $8^{\circ} \mathrm{C}$ ) dan perlakuan $\mathrm{C}$ (penggunaan quinaldine $1 \mathrm{cc} / 10 \mathrm{~L}$ dan suhu $8^{\circ} \mathrm{C}$ )

Prosedur penelitian meliputi tahap persiapan yaitu uji pendahuluan terhadap hewan uji mengenai suhu pembiusan, didapatkan suhu optimal untuk pembiusan yaitu $8^{\circ} \mathrm{C}$, sedangkan bahan metabolic yaitu quinaldine $1 \mathrm{cc} / 10 \mathrm{~L}$, dengan waktu pembiusan selama 15 menit. Tahap pelaksanaan yaitu pembiusan pada ikan mas sesuai dengan perlakuan dan masa perendaman selama 15 menit, memindahkan ikan yang telah terbius ke dalam akuarium yang telah diberi quinaldine 1cc/10L air tawar, mengamati aktivitas ikan mas saat pingsan dan masa siuman, dan mencatat secara akumulatif pada menit ke-0, 15, 30, 45, 60, 75, 90, 105, 120, 135. Kriteria ikan mas disebut pingsan adalah reaktivitas terhadap rangsangan luar tidak ada dan pergerakan operculum lambat. Masa siuman ikan mas diamati pada saat setelah ikan pingsan sampai kondisi ikan menjadi siuman. Sedangkan persentase masa siuman ikan mas diukur dengan menjumlahkan ikan mas yang siuman dibagi dengan jumlah keseluruhan ikan mas pada masing-masing perlakuan dikalikan seratus persen (Karnila, 2001). Untuk mengkaji dan menganalisis penggunaan perlakuan anestesi terhadap masa siuman ikan mas, maka semua data yang diperoleh dihimpun dalam bentuk tabulasi, selanjutnya dianalisis secara deskriptif.

\section{HASIL DAN PEMBAHASAN}

Pengamatan morfologi pada hewan uji setelah dimasukkan dalam media percobaan memperlihatkan bahwa pada mulanya ikan dalam kondisi tenang di dasar, beberapa detik kemudian gerakannya gelisah, terkadang naik turun, bahkan sering mulutnya membentur wadah. Sebelum ikan pingsan kerap kali ikan naik ke permukaan dengan gerakan tutup insang yang sangat cepat, seiring dengan itu ikan tidak bisa lagi mengendalikan fungsi normalnya sehingga ikan melayang dan jatuh ke dasar. Setelah itu ikan dinyatakan pingsan yang ditandai dengan posisi terlentang disertai gerakan operculum yang semakin lamban. Hal yang demikian terjadi pada semua perlakuan. Dalam keadaan seperti ini ikan tidak lagi bergerak, tetapi tutup insang tetap bergerak. Pengaruh perlakuan anestesi terhadap persentase masa siuman ikan mas tertuang pada Tabel 1 berikut : 
Tabel 1. Pengaruh perlakuan anestesi terhadap persentase masa siuman ikan mas

\begin{tabular}{|l|c|c|c|c|c|c|}
\hline \multirow{2}{*}{ Perlakuan Anastesi } & \multicolumn{7}{c|}{ Persentase (\%) } \\
\cline { 2 - 8 } & 30 & $\begin{array}{c}45 \\
\text { (menit) }\end{array}$ & $\begin{array}{c}60 \\
\text { (menit) }\end{array}$ & $\begin{array}{c}105 \\
\text { (menit) }\end{array}$ & $\begin{array}{c}120 \\
\text { (menit) }\end{array}$ & $\begin{array}{c}135 \\
\text { (menit) }\end{array}$ \\
\hline A (quinaldine 1cc/10L) & 0 & 60 & 100 & 100 & 100 & 100 \\
\hline B (suhu $8^{\circ} \mathrm{C}$ ) & 67 & 94 & 100 & 100 & 100 & 100 \\
\hline C (quinaldine 1cc/10L dan suhu $\left.8^{\circ} \mathrm{C}\right)$ & 0 & 0 & 0 & 34 & 67 & 100 \\
\hline
\end{tabular}

Sumber : Data primer diolah (2012)

Hasil analisis Tabel 1 di atas, perlakuan $\mathrm{B}$ ( suhu $8^{\circ} \mathrm{C}$ ) ikan mas sudah mulai siuman sebanyak $67 \%$ pada menit ke 30 , perlakuan A (quinaldine $1 \mathrm{cc} / 10 \mathrm{~L}$ ) pada menit ke 45 ikan mas siuman sebanyak $60 \%$ dan perlakuan B (suhu $8^{\circ} \mathrm{C}$ ) sebanyak $94 \%$. Pada perlakuan A (quinaldine $1 \mathrm{cc} / 10 \mathrm{~L}$ ) dan perlakuan $\mathrm{B}$ (suhu $8^{\circ} \mathrm{C}$ ), masa siuman ikan mas $100 \%$ pada menit ke 60 , sedangkan pada perlakuan $\mathrm{C}$ (quinaldine $1 \mathrm{cc} / 10 \mathrm{~L}$ dan suhu $8^{\circ} \mathrm{C}$ ) masa siuman ikan mas mulai terjadi pada menit ke 105 sebanyak $34 \%$, menit ke 120 sebanyak $67 \%$ dan menit 135 sebanyak $100 \%$.

Perbedaan masa siuman ikan mas pada masing-masing perlakuan anestesi dipengaruhi oleh bahan-bahan yang digunakan pada saat pembiusan. Menurut Berka (1986) bahwa penurunan suhu media dan penggunaan bahan-bahan pembius (anastesi) baik alami maupun buatan sangat membantu pada masa siuman dan penurunan metabolisme ikan. Metode pembiusan pada ikan ada beberapa cara diantaranya yaitu penggunaan suhu rendah dan penggunaan bahan antimetabolik. Penggunaan suhu rendah dapat dilakukan dengan dua cara yaitu (1) penurunan suhu secara langsung, dimana ikan langsung dimasukkan dalam air yang bersuhu $10-15^{\circ} \mathrm{C}$. Sehingga ikan akan pingsan; dan (2) penurunan suhu secara bertahap, dimana suhu air sebagai media ikan diturunkan secara bertahap sampai ikan pingsan (Berka, 1986).

Selanjutnya Erlina dan Wibowo (1995), menyatakan bahwa penggunaan bahan anti metabolik (quinaldine) digunakan untuk mengurangi metabolisme ikan dalam media, bahan anti metabolik (quinaldine) bila larut dalam air akan berfungsi mengecilkan laju aktivitas respirasi ikan atau mampu menurunkan konsumsi oksigen kurang lebih 20 persen dan tampaknya mampu meningkatkan kemampuan ikan untuk melawan konsentrasi oksigen rendah, sehingga meningkatkan jumlah ikan ver volume air. Quinaldine biasa digunakan sebagai bahan antiseptik dan antipyretic, selain itu, biasa digunakan untuk preparasi, termasuk obat anti malaria. Quinaldine (2-methylquinoline) sudah dipakai sebagai zat anestesi sejak dahulu, fungsinya menurunkan kinerja pernapasan (Karnila, 2001).

Cepatnya ikan mas pingsan diduga disebabkan oleh karakteristik obat bius yang digunakan berbeda, salah satu faktor yang mempengaruhi kecepatan pingsan adalah jumlah dosis yang digunakan, dan juga dipengaruhi oleh rendahnya kandungan oksigen dalam larutan. Obat bius adalah senyawa kimia yang dapat menyebabkan hilangnya seluruh atau sebagian rasa sebagai akibat dari penurunan fungs sel 
(Schreck dan Oyle, 1990). Untuk kepentingan hal tersebut, maka faktor-faktor seperti spesies ikan, umur, ukuran, daya tahan harus diperhatikan karena akan sangat berpengaruh pada kelangsungan hidup ikan. Selain itu, jenis obat bius yang digunakan sedapat mungkin memiliki daya bius yang cepat dan mudah terurai kembali. Pengaruh perlakuan anestesi terhadap kondisi ikan mas pada masa siuman tertuang pada Tabel 2 berikut :

Tabel 2. Pengaruh perlakuan anestesi terhadap kondisi ikan mas pada masa siuman

\begin{tabular}{|l|c|c|c|c|c|c|c|c|c|}
\hline \multirow{2}{*}{ Perlakuan Anastesi } & \multicolumn{7}{|c|}{ Masa Siuman (menit) } \\
\cline { 2 - 9 } A (quinaldine 1cc/10L) & $\begin{array}{c}\text { Belum } \\
\text { ber- } \\
\text { ubah }\end{array}$ & $\begin{array}{c}\text { Belum } \\
\text { ber- } \\
\text { ubah }\end{array}$ & $\begin{array}{c}\text { Sudah } \\
\text { ber- } \\
\text { ubah }\end{array}$ & $\begin{array}{c}\text { Gerak- } \\
\text { an } \\
\text { ambat }\end{array}$ & $\begin{array}{c}\text { Sudah } \\
\text { mulai } \\
\text { aktif }\end{array}$ & $\begin{array}{c}\text { Sudah } \\
\text { mulai } \\
\text { aktif }\end{array}$ & $\begin{array}{c}\text { Sudah } \\
\text { mulai } \\
\text { aktif }\end{array}$ & $\begin{array}{c}\text { Sudah } \\
\text { mulai } \\
\text { aktif }\end{array}$ & $\begin{array}{c}\text { Sudah } \\
\text { mulai } \\
\text { aktif }\end{array}$ \\
\hline B ( Suhu $8^{\circ} \mathrm{C}$ ) & $\begin{array}{c}\text { Belum } \\
\text { ber- } \\
\text { ubah }\end{array}$ & $\begin{array}{c}\text { Sudah } \\
\text { ber- } \\
\text { ubah }\end{array}$ & $\begin{array}{c}\text { Gerak- } \\
\text { an } \\
\text { lambat }\end{array}$ & $\begin{array}{c}\text { Sudah } \\
\text { mulai } \\
\text { aktif }\end{array}$ & $\begin{array}{c}\text { Sudah } \\
\text { mulai } \\
\text { aktif }\end{array}$ & $\begin{array}{c}\text { Sudah } \\
\text { mulai } \\
\text { aktif }\end{array}$ & $\begin{array}{c}\text { Sudah } \\
\text { mulai } \\
\text { aktif }\end{array}$ & $\begin{array}{c}\text { Sudah } \\
\text { mulai } \\
\text { aktif }\end{array}$ & $\begin{array}{c}\text { Sudah } \\
\text { mulai } \\
\text { aktif }\end{array}$ \\
\hline $\begin{array}{l}\text { C (quinaldine 1cc/10L dan } \\
\text { suhu } 8^{\circ} \mathrm{C} \text { ) }\end{array}$ & $\begin{array}{c}\text { Belum } \\
\text { ber- } \\
\text { ubah }\end{array}$ & $\begin{array}{c}\text { Belum } \\
\text { ber- } \\
\text { ubah }\end{array}$ & $\begin{array}{c}\text { Belum } \\
\text { ber- } \\
\text { ubah }\end{array}$ & $\begin{array}{c}\text { Belum } \\
\text { ber- } \\
\text { ubah }\end{array}$ & $\begin{array}{c}\text { Belum } \\
\text { ber- } \\
\text { ubah }\end{array}$ & $\begin{array}{c}\text { Belum } \\
\text { ber- } \\
\text { ubah }\end{array}$ & $\begin{array}{c}\text { Sudah } \\
\text { ber- } \\
\text { ubah }\end{array}$ & $\begin{array}{c}\text { Gerak- } \\
\text { an } \\
\text { lambat }\end{array}$ & $\begin{array}{c}\text { Sudah } \\
\text { mulai } \\
\text { aktif }\end{array}$ \\
\hline
\end{tabular}

Sumber : Data primer diolah (2012)

Hasil analisis Tabel 2 di atas, pada saat ikan dimasukkan kedalam air yang mengandung quinaldine $1 \mathrm{cc} / 10 \mathrm{~L}$ dengan suhu $15^{\circ} \mathrm{C}$, penggunaan bahan ini dilakukan pada masa transportasi untuk mempertahankan masa siuman. Untuk masa siuman ikan selama 15 menit sampai 30 menit, kondisi ikan belum berubah dan masih roboh, respon tidak ada, dan tidak meronta. Pada perlakuan $\mathrm{B}$ ( suhu $8^{\circ} \mathrm{C}$ ) pada menit ke 45 sudah mulai ada gerakan lambat, sedikit responsif sedangkan pada kedua perlakuan belum memberikan respon (belum berubah) dan masih roboh di dasar. Pada menit ke 60 untuk suhu $8^{\circ} \mathrm{C}$ ikan sudah mulai aktif, responsif dan gesit, pada perlakuan A (quinaldine $1 \mathrm{cc} / 10 \mathrm{~L}$ ) terjadi pada menit ke 75 , sedangkan pada $\mathrm{C}$ (quinaldine $1 \mathrm{cc} / 10 \mathrm{~L}$ dan suhu $8^{\circ} \mathrm{C}$ ) masa siuman (gerakan lambat) mulai nampak pada menit ke 120 dan setelah melewati masa fase tersebut ikan sudah tegak kokoh, aktif, responsif dan gesit. Menurut Suwardi (2008) bahwa penggunaan suhu dan bahan antimetabolik (quinaldine) membantu meningkatkan masa siuman sehingga sangat membantu dalam proses metabolisme ikan.

Hasil analisis pengaruh anestesi terhadap masa siuman ikan mas ini perbedaan hanya terlihat dalam kecepatan ikan sadar kembali, di mana semakin cepat proses pembiusan maka semakin cepat pula ikan sadar kembali dan energi yang dibutuhkan semakin sedikit. Hal ini sesuai dengan pendapat Suwardi (2008) bahwa suhu ruangan sangat membantu proses masa siuman, semakin tinggi suhu maka semakin cepat terjadinya siuman dan sebaliknya semakin rendah suhu maka semakin lama masa siuman ikan. 


\section{KESIMPULAN}

Berdasarkan hasil penelitian dapat diambil kesimpulan bahwa penggunaan perlakuan anestesi pada masa siuman ikan mas yang terbaik pada perlakuan $\mathrm{C}$ yaitu penggabungan penggunaan quinaldine $1 \mathrm{cc} / 10 \mathrm{~L}$ dan penggunaan suhu $8^{\circ} \mathrm{C}$.

\section{DAFTAR PUSTAKA}

Berka, 1986. The Transport of Live Fish. EIFAC. FAO. (48):52.

Erlina, dan S. Wibowo, 1995. Studi Penggunaan Metode Pembiusan Langsung dengan Suhu Rendah dalam Transportasi Sistem Kering Udang Windu (Penaeus monodon). Jurnal Penelitian Pasca Panen Perikanan.

Karnila, 2001. Pengaruh Suhu dan Waktu Pembiusan Bertahap Terhadap Ketahanan Ikan. Jurnal Natur Indonesia III: 151-167.

Praseno, 1990. Cara Pengiriman atau Transportasi Ikan dalam Keadaan Hidup. Makalah pada Pertemuan Aplikasi Paket Teknologi (Temu Taga) Badan Penelitian dan Pengembangan Pertanian. Bogor.

Suseno, D., 1994. Pengelolaan Usaha Pembenihan Ikan Mas. Penebar Swadaya. Bogor. Suwardi, 2008. Penggunaan Phenoxy Ethanol, Suhu Dingin dalam Pembiusan Bandeng. Media Akuakultur Volume 3 Nomor 2. 